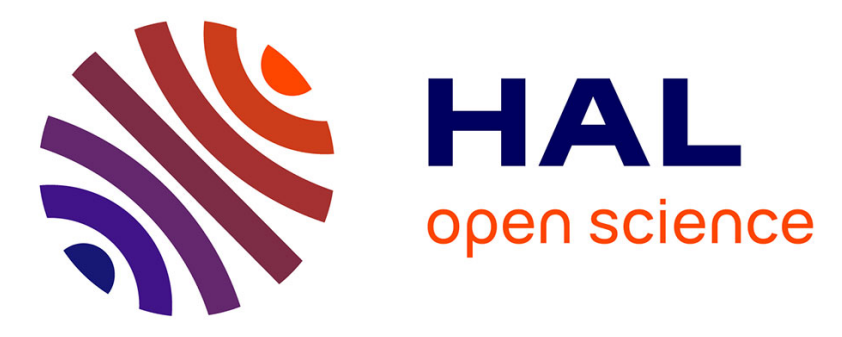

\title{
Numerical simulation of dome filling in an experimental rocket engine mockup
}

\author{
Marie-Charlotte Gauffre, Hervé Neau, Olivier Simonin, Renaud Ansart, \\ Nicolas Meyers, Stéphane Petitot
}

\section{- To cite this version:}

Marie-Charlotte Gauffre, Hervé Neau, Olivier Simonin, Renaud Ansart, Nicolas Meyers, et al.. Numerical simulation of dome filling in an experimental rocket engine mockup. Journal of Propulsion and Power, 2014, vol. 30, pp. 617-627. 10.2514/1.B34904 . hal-01015844

\author{
HAL Id: hal-01015844 \\ https://hal.science/hal-01015844
}

Submitted on 27 Jun 2014

HAL is a multi-disciplinary open access archive for the deposit and dissemination of scientific research documents, whether they are published or not. The documents may come from teaching and research institutions in France or abroad, or from public or private research centers.
L'archive ouverte pluridisciplinaire HAL, est destinée au dépôt et à la diffusion de documents scientifiques de niveau recherche, publiés ou non, émanant des établissements d'enseignement et de recherche français ou étrangers, des laboratoires publics ou privés. 


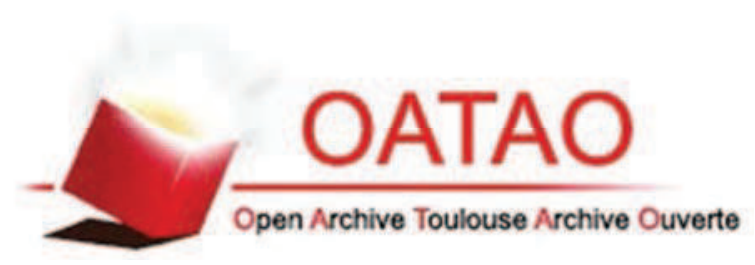

\section{Open Archive TOULOUSE Archive Ouverte (OATAO)}

OATAO is an open access repository that collects the work of Toulouse researchers and makes it freely available over the web where possible.

This is an author-deposited version published in : http://oatao.univ-toulouse.fr/ Eprints ID : 11736

To link to this article : DOI: 10.2514/1.B34904

URL : http://dx.doi.org/10.2514/1.B34904

To cite this version : Gauffre, Marie-Charlotte and Neau, Hervé and Simonin, Olivier and Ansart, Renaud and Meyers, Nicolas and Petitot, Stéphane Numerical simulation of dome filling in an experimental rocket engine mockup. (2014) Journal of Propulsion and Power, vol. 30 ( $\left.n^{\circ} 3\right)$. pp. 617-627. ISSN 0748-4658

Any correspondance concerning this service should be sent to the repository administrator: staff-oatao@1istes-diff.inp-toulouse.fr 


\title{
Numerical Simulation of Dome Filling in an Experimental Rocket Engine Mockup
}

\author{
M.-C. Gauffre, ${ }^{*}$ H. Neau, ${ }^{\dagger}$ O. Simonin, ${ }^{\ddagger}$ and R. Ansart ${ }^{\S}$ \\ Université de Toulouse, IMFT, Allée du Professeur Camille Soula, \\ FR-31400 Toulouse, France \\ N. Meyers ${ }^{\top}$ \\ Snecma Vernon, Forêt de Vernon, FR-27208 Vernon Cedex, France \\ and \\ S. Petitot ${ }^{* *}$ \\ Centre National d'Études Spatiales, DLA, 52, Rue Jacques Hillairet, FR-75612 Paris Cedex,
}

France

DOI: 10.2514/1.B34904

\begin{abstract}
Experiments are carried out with substitution fluids (air and water), without heat and mass transfer on a rocket engine mockup. The work presented here intends to reproduce the experimental results using incompressible twophase flow simulations. The geometry used is representative of the experimental mockup composed of a feeding pipe, a dome, and a number of injectors. The objective of the paper is to adapt a Eulerian-Eulerian two-fluid model approach to simulate the filling of a dome and to test its ability to reproduce some experimental evidences. The main difficulties to be faced are the fast transients in a complex geometry, including in particular the valve opening sequence, and the drastic evolution of the two-phase flow regime as the flow evolves from gas only to liquid only. An important work has been conducted to obtain the proper inlet conditions to be imposed in the code in coherence with the experiments. The influences of the turbulence modeling and the interfacial momentum transfer modeling are also studied. The former has no macroscopic or local effect on the mass flow rate of water, the mass of water in the dome, and the dome pressure. The drag model, however, has a major impact on the results as much globally as locally. The Simmer-like drag model is preferred in comparison to the Large Interface Model, due to a better agreement with the experimental data. Moreover, it has to be highlighted that the Simmer-like model is very sensitive to the inclusion diameter.
\end{abstract}

\begin{tabular}{|c|c|c|}
\hline & & Nomenclature \\
\hline$a$ & $=$ & date of the first wet injector, $\mathrm{s}$ \\
\hline$b$ & $=$ & date of the slope beginning, $s$ \\
\hline$C_{D}$ & $=$ & drag coefficient \\
\hline & $=$ & injection slope, $\mathrm{s}^{-1}$ \\
\hline$D$ & $=$ & pipe diameter, $\mathrm{m}$ \\
\hline$d$ & $=$ & $\begin{array}{l}\text { distance between the disc center and the } \\
\text { ellipse center, } m\end{array}$ \\
\hline$d_{i}$ & $=$ & inclusion diameter, $\mathrm{m}$ \\
\hline$F$ & $=$ & drag force by mass unit, $\mathrm{N} \cdot \mathrm{kg}^{-1}$ \\
\hline$I_{u}$ & $=$ & inlet turbulence intensity \\
\hline$k$ & $=$ & number of phase \\
\hline$L$ & $=$ & valve path length, $\mathrm{m}$ \\
\hline
\end{tabular}

*Ph.D. Student, CNRS, Institut de Mécanique des Fluides de Toulouse, FR-31400 Toulouse, France; Centre National d'Études Spatiales, DLA, 52, rue Jacques Hillairet, FR-75612 Paris Cedex, France; marie-charlotte .gauffre@imft.fr.

Research Engineer, CNRS, Institut de Mécanique des Fluides de Toulouse, FR-31400 Toulouse, France; herve.neau@imft.fr.

¥Professor, CNRS, Institut de Mécanique des Fluides de Toulouse, FR-31400 Toulouse, France; olivier.simonin@imft.fr.

${ }^{\S}$ Assistant Professor, CNRS, Institut de Mécanique des Fluides de Toulouse, FR-31400 Toulouse, France; renaud.ansart@ensiacet.fr.

"Research Engineer; nicolas.meyers@ snecma.fr.

**Research Engineer, DLA; stephane.petitot@ cnes.fr.

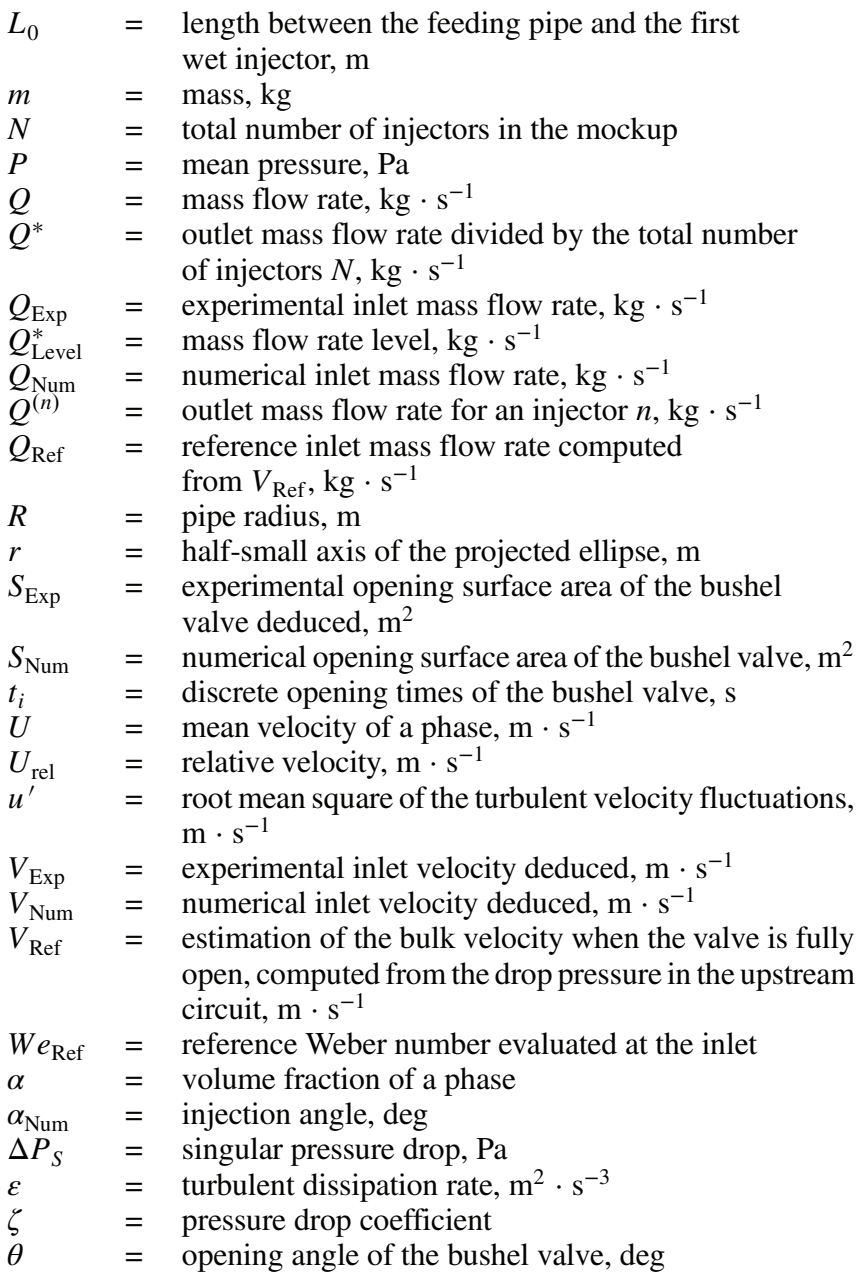




$\begin{array}{lll}\mu & = & \text { dynamic viscosity, } \mathrm{Pa} \cdot \mathrm{s} \\ \rho & = & \text { density, } \mathrm{kg} \cdot \mathrm{m}^{-3} \\ \sigma & = & \text { surface tension, } \mathrm{N} \cdot \mathrm{m}^{-1} \\ \tau_{0} & = & \text { opening time of the bushel valve, } \mathrm{s} \\ \chi & = & \text { number fraction of wet injectors }\end{array}$

\section{Introduction}

$\mathbf{N}$ EW generation cryogenic upper-stage rocket engines are planned to be restartable during the orbit mission $[1,2]$. The reignition of the engine is particularly difficult in space flight conditions. The engine contains a liquid oxygen (LOX) dome fed with LOX supplied by a main valve through a pipe. As soon as the main valve is opened, LOX enters the dome, which is already swept by a helium venting at ambient temperature. The gas-liquid mixture forming in the dome is injected into the combustion chamber through a number of injectors. Therefore, the two-phase flow distribution at injectors outlet carries a real importance in terms of the ignition from the opening to the closing phases of the main valve. The flight conditions are of paramount importance to study the flow in the dome and at the injectors outlet; however, they are truly difficult to reproduce by experimental ground tests. To understand the phenomena at stake, experimental and numerical studies have been carried out in a simplified configuration.

The objective of the paper is to adapt a Eulerian-Eulerian two-fluid model approach to simulate the filling of a dome and to test its ability to reproduce some experimental evidences. The main difficulties to be faced are the fast transients in a complex geometry, including in particular the valve opening sequence, and the drastic evolution of the two-phase flow regime as the flow evolves from gas only to liquid only. The work has been carried out at the Fluid Mechanics Institute in Toulouse, France using the code NEPTUNE_CFD, and the results are compared with the experimental data supplied by the Geophysical and Industrial Flows Laboratory (LEGI) in Grenoble, France. In these experiments, liquid water and air are, respectively, used instead of LOX and helium; the dome walls are adiabatic; and the flashing phenomenon is not considered.

\section{Experimental Setup}

An experimental program has been set up at LEGI [3] in order to study the flow in the dome, without the flashing phenomenon. The matter at hand is both to understand and to identify the phenomena at stake in the transient dome feeding and to build a database, so as to validate the developments in the code models. Thus, a series of test campaigns was carried out on an experimental test bed.

\section{A. Description of the Experimental Setup}

The LOX dome of the rocket engine is represented in the experimental mockup at LEGI in a simplified manner by a toric volume, which keeps the volume of the real dome (Fig. 1). This experimental model is made up of a dome, a feeding pipe upstream, $N$ injectors downstream, and an igniter pipe in its center. At the feeding pipe inlet, liquid injection is controlled by a bushel valve that can rotate between $\theta=0$ and $90 \mathrm{deg}$.

\section{B. Experimental Conditions}

The experiment consists of a representative model of the injection dome filled with substitution fluids according to a reference Weber number defined by $W e_{\text {Ref }}=\rho_{1} V_{\text {Ref }}^{2} D / \sigma$, where $\rho_{1}$ is the density of liquid, $V_{\mathrm{Ref}}$ is an estimation of the bulk velocity when the valve is fully open, computed from the drop pressure in the upstream circuit, $D$ is the pipe diameter, and $\sigma$ is the surface tension. Water is the filling fluid, whereas air is the fluid initially in the dome. Moreover, these experiments were carried out without heat and mass transfer: dome walls are not heated, and the two fluids are at the same temperature. Water flow at the feeding pipe inlet is controlled by a spherical bushel valve, which ideally opens between $\theta=0$ and 90 deg linearly during the opening time of the bushel valve $\tau_{0}=100 \mathrm{~ms}$. Then, during the plateau stage of $500 \mathrm{~ms}$, the valve remains open at its maximum angle $(\theta=90 \mathrm{deg})$. Finally, the valve requires an additional $500 \mathrm{~ms}$ to

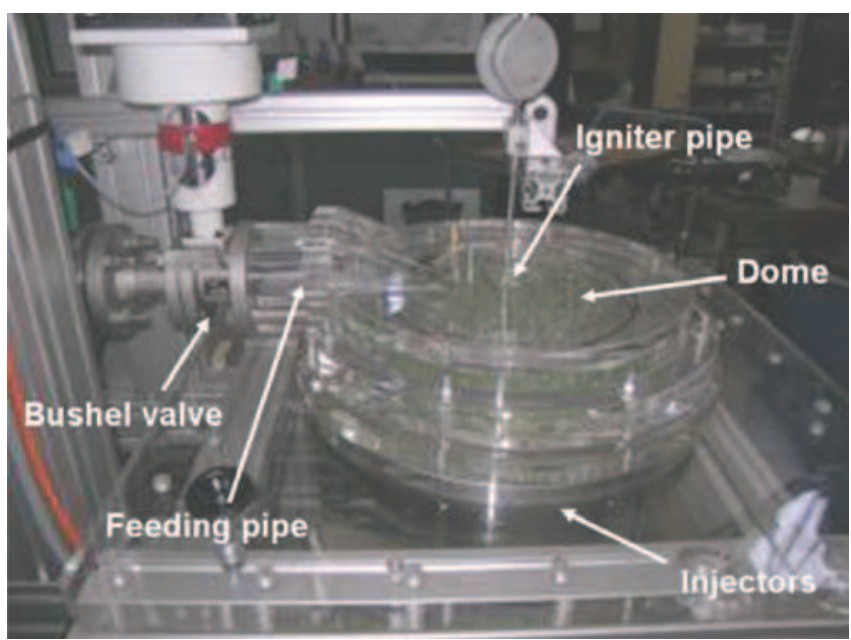

Fig. 1 Experimental mockup at LEGI.

completely close $(\theta=0 \mathrm{deg})$. It has to be noted that the liquid enters the feeding pipe for valve rotation angles in the range of 19.6 to $90 \mathrm{deg}$.

\section{Measurements Carried Out at LEGI}

During the experiments at LEGI, several measurements were carried out with a complete opening of the bushel valve. Pressure was measured in the dome. Moreover, imaging techniques in white light were used to visualize the flow in the transparent polymethyl methacrylate (PMMA)-made dome. Imaging techniques by laser sheet also permitted the experimenters to visualize the injectors outlet: the laser sheets detect if water comes out of the injectors outlet, and therefore it is possible to determine if the injectors are "wet" or not. It has to be noted that this process can not detect more than 70 "wet" injectors, for the moment.

\section{Numerical Setup}

\section{A. Computational Domain}

The simulations are conducted on an unstructured threedimensional (3-D) mesh shown by Fig. 2. This mesh is the result of the merging of noncoincident meshes, composed of $1.124 \times 10^{6}$ hexahedra. Because of the complexity of the geometry, the use of an unstructured mesh is needed. The geometry is equivalent to the experimental mockup. This industrial geometry is composed of a feeding pipe, a dome with $N$ injectors, and an igniter pipe in its center.

\section{B. Physical Modeling}

As in the experiments, the dome is initially filled with air. Water is injected at the pipe inlet. For the simulations, separate phases (water and air) are considered to be incompressible, without heat and mass transfer. The behavior of a fluid mixture made of several physical phases or components can be modeled using the general Eulerian

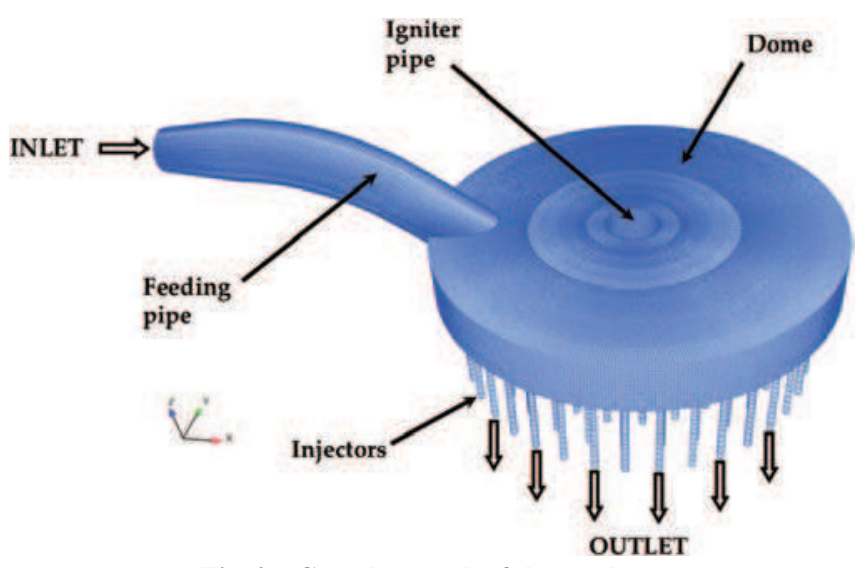

Fig. 2 Complete mesh of the mockup. 
multifield balance equations. For each phase, the mass balance and the momentum balance equations are solved ( $k=1$ is for the liquid phase, and $k=2$ is for the gas phase). More details can be found in [4-6]. The $k-\varepsilon$ turbulence model is activated for both phases. Concerning the interfacial momentum transfer modeling, only drag and mean pressure gradient (Archimedes) forces are taken into account.

In the reference case, the Simmer-like model [7] is a standard choice to model the drag force. This drag model is fitted to have a physical behavior in the limits: it considers either dispersed gas bubbles in a continuous liquid flow or dispersed liquid droplets in a continuous gas flow with regard to the volume fraction. Thus, the Simmer-like law corresponds to the liquid droplets drag law in a continuous gas flow when the volume fraction is lower than 0.3 and to the gas bubbles drag law in a continuous liquid flow when the volume fraction of water is greater than 0.7. For intermediate volume fractions, the drag law is calculated by cubic interpolation between these two limits. The $i$ th component of the drag force $F_{i}$ by mass unit is given by the following equations:

$$
\begin{gathered}
F_{i}=F_{1, i}=-\frac{3}{4} \frac{\rho_{2}}{\rho_{1}} \frac{C_{D 1}}{d_{1}}\left|U_{\text {rel }}\right| U_{\text {rel }, i} \quad \text { if } \alpha_{1} \leq 0.3 \\
F_{i}=F_{2, i}=-\frac{3}{4} \frac{\rho_{1}}{\rho_{2}} \frac{C_{D 2}}{d_{2}}\left|U_{\text {rel }}\right| U_{\text {rel }, i} \quad \text { if } \alpha_{1} \geq 0.7 \\
F_{i}=f\left(F_{1, i}\left(\alpha_{1}=0.3\right), F_{2, i}\left(\alpha_{1}=0.7\right)\right) \quad \text { if } 0.3 \leq \alpha_{1} \leq 0.7
\end{gathered}
$$

where $\alpha_{1}$ is the volume fraction of liquid; $\rho_{1}$ and $\rho_{2}$ are, respectively, the density of the liquid and gas; $d_{2}$ and $d_{1}$ represent, respectively, the characteristic diameter of the droplets and bubbles; $U_{\text {rel }, i}$ is the $i$ th component of the relative velocity between the two phases; $f$ defines the cubic interpolation; and $C_{D}$ is the drag coefficient. This coefficient is defined by

$$
C_{D}=\frac{24 \nu_{c}}{\left|U_{\text {rel }}\right| d_{p}}\left(1+0.15\left(\frac{\left|U_{\text {rel }}\right| d_{p}}{\nu_{c}}\right)^{0.687}\right)
$$

where index $p$ corresponds to the dispersed phase, index $c$ corresponds to the continuous phase, and $\nu$ is the kinematic viscosity.

Nonetheless, this model is not adapted to pure stratified flows, because the Simmer-like law may lead to a significant overevaluation or underestimation of the friction between the gas and the liquid. Furthermore, the drag model based on the friction between a dispersed and a continuous phase is sensitive to the diameter value. The uniform diameter imposed is a strong limitation. This diameter should at minimum depend on the Weber number, and even it should ideally depend on time and space according to an interfacial area transport equation. Nonetheless, this model is widely used for flows such as in nuclear applications with strong variations of volume fraction, and so an alternative to model the friction is the Large Interface Model (LIM) [8,9], implemented in the code and validated by Électricité de France (EDF) Research and Development from experimental measurements [10]. This method allows us to locate the free surface and takes into account momentum and turbulence exchanges between phases. First, the free surface is located and built from the local gradient of the volume fraction, thanks to the refinedgradient method. Then, in this three-cell layer built around the interface, liquid and gas characteristic tangential velocities are determined, in order to calculate interfacial velocity and momentum exchange, considering wall function on both sides.

\section{Initial Conditions}

The mockup is initially filled with air (in phase $k=2$ ). The density of air is $\rho_{2}=1.2 \mathrm{~kg} / \mathrm{m}^{3}$, and the dynamic viscosity of air is $\mu_{2}=1.85 \times 10^{-5} \mathrm{~Pa} \cdot \mathrm{s}$. As regards the initial conditions concerning the turbulence, they are constant and based on the flow characteristics when the bushel valve is fully open.

\section{Boundary Conditions}

\section{Inlet Boundary Conditions}

Water is injected at the pipe inlet, with density $\rho_{1}=1000 \mathrm{~kg} / \mathrm{m}^{3}$ and dynamic viscosity $\mu_{1}=10^{-3} \mathrm{~Pa} \cdot \mathrm{s}$. As stated previously, a reference Weber number is evaluated at the inlet: $W e_{\operatorname{Ref}}=\rho_{1} V_{\operatorname{Ref}} D / \sigma$, where $V_{\text {Ref }}$ is an estimation of the bulk velocity when the valve is fully open, computed from the drop pressure in the upstream circuit; $D$ is the pipe diameter; and $\sigma$ is the surface tension. If the $k-\varepsilon$ turbulence model is activated, this Weber number imposes turbulent kinetic energy $q_{1}^{2}=3 / 2\left(V_{\text {Ref }} I\right)^{2}$ and turbulent dissipation rate $\varepsilon_{1}=C_{\mu}\left(q_{1}^{2}\right)^{3 / 2} l^{-1}$, where $I_{u}=u^{\prime} / V_{\mathrm{Ref}}$ is the inlet turbulence intensity, with $u^{\prime}$ the root mean square of the turbulent velocity fluctuations, $C_{\mu}=0.09$, and $l=0.03 D$ the turbulence length scale. This injection takes into account the complete opening between 0 and $90 \mathrm{deg}$ of the bushel valve to be in the same conditions as the experiments at LEGI. It implies that modifications of the liquid velocity vector field, inlet surface area, and inlet mass flow rate due to the angular position of the valve have to be taken into account.

The inlet experimental data are the inlet mass flow rate of water and the opening angle $\theta$ of the bushel valve. Thus, there is still the need to determine the temporal evolution of the opening surface area of this valve. As a first approximation, the 3-D geometric problem of the valve opening is turned into a two-dimensional (2-D) problem in the same plane as the inlet mesh of the feeding pipe (Fig. 3).

To convert the problem into a 2-D one, we consider a fixed disc at the feeding pipe inlet plane and a mobile disc at the bushel valve plane. Instantaneous projection of the mobile disc onto the plane of the fixed disc is an ellipse on this latter plane. This instantaneous ellipse, and in particular its center $\left(0^{\prime}\right)$ and its half-small axis $(r)$, will then evolve according to the rotational motion of the valve. After some calculations, area $S_{\text {Exp }}$ of the intersection surface is

$$
\begin{aligned}
S_{\text {Exp }} & =R^{2} \cos ^{-1}\left(\frac{d}{R+r}\right)-\frac{R^{2} d}{R+r} \sin \left(\cos ^{-1}\left(\frac{d}{R+r}\right)\right) \\
+ & \frac{1}{2} \cos ^{-1}\left(\frac{d}{R+r}\right)\left(r^{2}+R^{2}\right)-\frac{R^{2}-r^{2}}{4} \sin \left(2 \cos ^{-1}\left(\frac{d}{R+r}\right)\right) \\
& -\frac{r d R}{R+r} \sin \left(\cos ^{-1}\left(\frac{d}{R+r}\right)\right)
\end{aligned}
$$

where $\theta$ is the opening angle of the bushel valve, $D$ is the pipe diameter, $R=D / 2$ is the pipe radius, $L$ is the valve path length, $d=L \cos \theta / 2$ is the distance between the disc center and the ellipse center, and $r=D \sin \theta / 2$ is the half-small axis of the projected ellipse.

Actually, the temporal evolution of opening surface area $S_{\operatorname{Exp}}$ is expressed as a function of $\theta$, the opening angle of the bushel valve. As the opening law of the valve is provided by the experimental data at LEGI, the evolution of experimental opening surface area $S_{\text {Exp }}$ (calculated "theoretically") can be deduced.

The second issue is that the inlet mesh of the pipe is discrete. Thus, we need to determine which cells are well in the open inlet area of the valve, called $S_{\text {Num }}$. For that, the open inlet area cells are detected thanks to a second reduction: these cells are in the open area if they are a part of an ellipse area with center $I$, half-small axis $1 / 2 \mathrm{JK}$, and halfbig axis $I M$. Therefore, we can say that coordinates $(y, z)$ of these open inlet area cells verify

$$
\left(\frac{y-y_{I}}{\frac{1}{2} J K}\right)^{2}+\left(\frac{z-z_{I}}{I M}\right)^{2} \leq 1
$$

which is then used directly by the code to assess the possible numerical opening surface area $S_{\mathrm{Num}}$. By comparison of the values of $S_{\text {Num }}$ and $S_{\text {Exp }}$, we can deduce the opening times of the valve $t_{i}$, then the inlet mass flow rate of water corresponding to $Q_{\text {Exp }}\left(t_{i}\right)$ (which is interpolated in the code), and finally numerical velocity $V_{\mathrm{Num}}\left(t_{i}\right)$ given by 


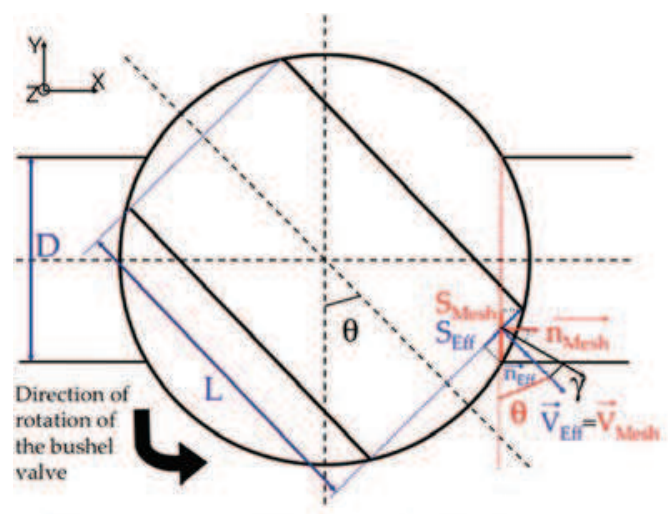

a) 3-D geometric problem (on the $\mathrm{X}-\mathrm{Y}$ plane)

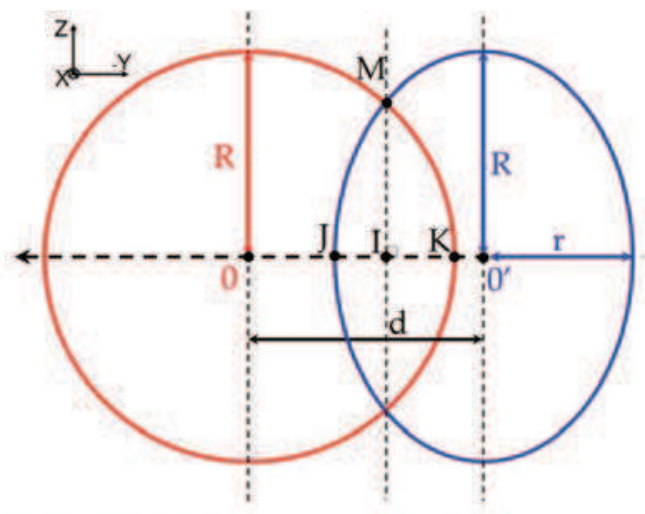

b) Simplified 2-D approach (on the Y-Z plane)

Fig. 3 3-D geometric problem of the bushel valve turned into a 2-D problem in the same plane.

$$
V_{\mathrm{Num}}\left(t_{i}\right)=\frac{Q_{\mathrm{Exp}}\left(t_{i}\right)}{S_{\mathrm{Num}}\left(t_{i}\right) \rho_{1} \cos \left(\alpha_{\mathrm{Num}}\right)}
$$

where $\alpha_{\text {Num }}=\pi / 2-\theta^{\prime}$ is the inlet injection angle, with $\theta^{\prime}=$ $\theta+\gamma=\theta+\arctan ^{-1}\left(\frac{\cos (\theta)}{1+\sin (\theta)}\right)(\theta$ and $\gamma$ are represented in Fig. 3a). A study (not presented here) reveals that injection angle $\alpha_{\text {Num }}$ of the inlet velocity has few effects on the results. Therefore, $\alpha_{\text {Num }}$ is calculated to be the most close to the real opening of the bushel valve.

\section{Outlet Boundary Conditions}

At each injector outlet, we impose a free outlet pressure and a singular pressure drop $\Delta P_{S}=1 / 2 \zeta \rho_{k} U_{k}^{2}$ distributed on the four bottom cells of each injector, with pressure drop coefficient $\zeta=1$ in order to model the experimental sudden expansion at the injectors outlet.

\section{Wall Boundary Conditions}

Along the walls, standard turbulent friction functions are used for both phases.

\section{E. Numerical Solver}

The 3-D numerical simulations presented in this paper are performed with NEPTUNE_CFD V1.08, with the physical modeling introduced in Sec. III B.

This code is a finite volume Eulerian multiphase flow solver parallelized [11,12]. More precisely, all types of cells can be used for meshes with the possibility of nonconforming connections. All the variables are located at the center of the cells, and colocalized gradients are calculated with reconstruction methods.

In the code, the partial differential equations are discretized with a second-order centered scheme, and the solution is time advanced by a first-order scheme.

Mass, momentum, and energy equations are coupled with the help of a pressure correction equation, within the iterative "alphapressure-energy" step. The algorithm allows density variation according to pressure and enthalpy during a time step (refer to [13,14] for more information).

\section{Results}

The aim of this work is to demonstrate the feasibility of a 3-D unsteady two-phase flow calculation to study the LOX dome filling, taking into account the real geometry and the preponderant physical phenomena. In this section, a reference case is first presented. The comparison of the predictions with the experimental results is carried out in order to estimate the code capability to predict the flow behavior, according to available closure laws. Then this work focuses on sensitivity studies on the closure laws to assess their influence on the numerical predictions.

\section{A. Reference Case and Comparisons with the Experimental Data}

1. Validation of the Valve Opening Implementation

According to comparisons between the inlet data implemented in the code and the experimental data, the preliminary validation of the valve opening is presented in this first part.

Opening surface area $S_{\text {Exp }}$, corresponding to experimental opening valve angle $\theta$, is compared with the numerical inlet boundary condition in Fig. 4. As stated previously, the inlet mesh of the feeding pipe is discrete, which is why numerical surface area $S_{\mathrm{Num}}$ is crenellated. In this figure and the following ones, the dashdotted lines indicate the instants corresponding to the different positions of the bushel valve: the first one for the effective beginning of the valve opening $(\theta=19.6 \mathrm{deg}$ at $t=0.123 \mathrm{~s})$, the second one when the valve is fully open $(\theta=90 \mathrm{deg})$, and the third one when the valve begins to close up to $\theta=19.6 \mathrm{deg}$, which is marked by the last red line. When $\theta<19.6 \mathrm{deg}$, the valve is effectively closed and there is no inlet mass flow rate of water. Therefore, the numerical simulations really start when $\theta=19.6 \mathrm{deg}$ (at $t=0.123 \mathrm{~s}$ ) to spare time, whereas the experiments begin before at $t=0 \mathrm{~s}$. Thus, in the following figures, the time origin is $t=0.123 \mathrm{~s}$, in order to be more clear.

Figure 5 shows the comparison between the experimental inlet mass flow rate and the numerical inlet boundary condition. The relative deviation of the inlet mass flow rate of water is lower than $1 \%$ in absolute terms, which shows a good agreement between the experimental and the numerical data.

\section{Points of Comparison}

To compare the numerical results with the experimental data, it is interesting to set up common points of comparison.

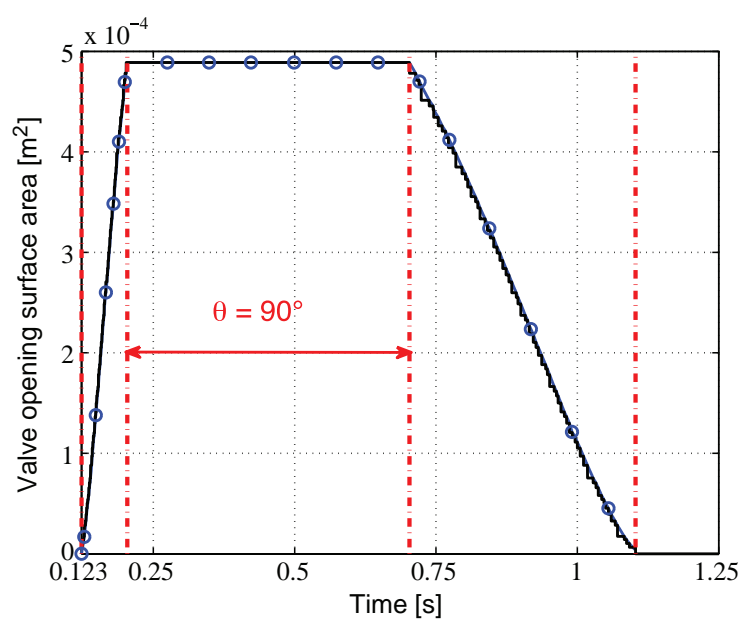

Fig. 4 Comparisons between the experimental inlet data and the numerical inlet boundary condition for the opening surface area. - , experimental inlet data; — numerical inlet boundary condition. 


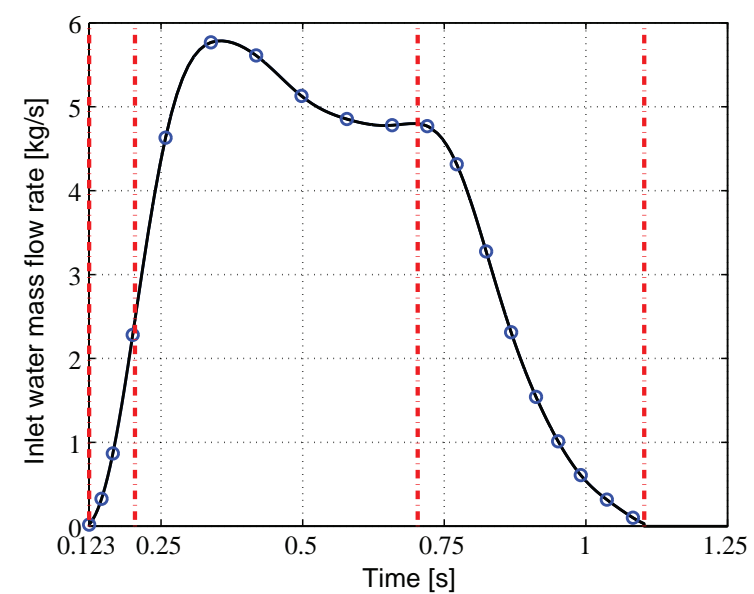

Fig. 5 Comparison between the experimental inlet data and the numerical inlet boundary condition for the water mass flow rate. - - experimental inlet data; $\longrightarrow$, numerical inlet boundary condition.

The first point is the pressure measured in the dome. To follow its temporal evolution, a probe is placed at the same position as in the experiments, at the top of the dome behind the igniter pipe.

A second point of comparison is the temporal evolution of the number fraction of wet injectors named $\chi$. The number fraction $\chi$ is the fraction of the number of wet injectors to the total number of injectors. Experimentally, an injector is said to be "wet" if a drop of water is detected at the injector outlet by the laser sheet. Numerically, this experimental criterion is not valid: it is impossible to detect a drop of water at the injector outlet because the volume fraction of water is never totally null during the Eulerian simulations. Therefore, a numerical "wet" level is equally defined: an injector is defined as "wet" if the mass flow rate of water is higher than a certain level $Q_{\mathrm{Level}}^{*}$, defined as a part of $Q_{\mathrm{Ref}}^{*}$. Knowing that this mockup is made up of $N$ injectors and assuming that the distribution of liquid at each injector outlet is the same, we define a reference mass flow rate per injector $Q_{\mathrm{Ref}}^{*}=Q_{\mathrm{Ref}} / N$, where $Q_{\mathrm{Ref}}$ is the reference inlet mass flow rate computed from $V_{\text {Ref }}$.

According to the temporal evolution of the number fraction of wet injectors $\chi$, it is possible to determine three criteria for $\chi: 1$ ) the date of the first wet injector, $a$; 2) the date of the slope beginning, $b$; and 3 ) the injection slope, $c$.

As an example, the temporal evolution of the number fraction of wet injectors is represented in Fig. 6, with the three wet criteria $a, b$, and $c$.

Additionally, LEGI has developed a zero-dimensional model that permits an approximation of the temporal evolution of the number fraction of wet injectors [3]. This law is given by

$$
\begin{gathered}
\chi(t)=0 \quad \text { if } t \leq \tau_{\mathrm{inj}}^{0} \\
\chi(t)=\frac{t-\tau_{\mathrm{inj}}^{0}}{\tau_{\mathrm{inj}}} \quad \text { if } \tau_{\mathrm{inj}}^{0} \leq t \leq \tau_{\mathrm{inj}}^{0}+\tau_{\mathrm{inj}} \\
\chi(t)=1 \quad \text { if } t \geq \tau_{\mathrm{inj}}^{0}+\tau_{\mathrm{inj}}
\end{gathered}
$$

where $\tau_{\text {inj }}^{0}=3.4 \tau_{0}\left(T_{0} / \tau_{0}\right)^{0.75} ; \tau_{\text {inj }}+\tau_{\text {inj }}^{0}=3.87 \tau_{0}\left(T_{0} / \tau_{0}\right)^{0.68} ; \tau_{0}$ is the opening time of the bushel valve; $T_{0}=L_{0} / V_{\text {Ref }}$ is the time of flight of a fluid particle traveling the length $L_{0}$ between the feeding pipe inlet and the first wet injector outlet with the inlet velocity of liquid $V_{\text {Ref }}$, an estimation of the bulk velocity when the valve is fully open, computed from the drop pressure in the upstream circuit. It has to be noted that in the theoretical wet law criterion $a$ is the same as criterion $b$. That is why the analysis of the numerical results will be led only on criteria $b$ and $c$.

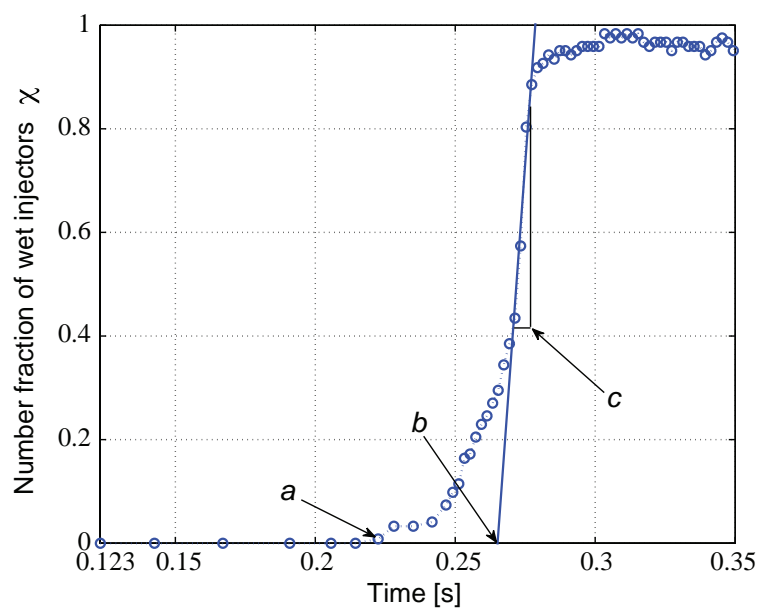

Fig. 6 Representation of the three wet criteria $(a, b$, and $c)$ on the temporal evolution curve of the number fraction of wet injectors.

\section{Results of the Reference Case}

The reference case presented here is performed for a reference Weber number $W e_{\text {Ref }}=4.72 \times 10^{4}$, that is to say, $V_{\text {Ref }}=11.5 \mathrm{~m} / \mathrm{s}$ and $Q_{\text {Ref }}=5.65 \mathrm{~kg} / \mathrm{s}$. The $k-\varepsilon$ turbulence model is activated. The reference inlet velocity $V_{\text {Ref }}$ imposes the turbulent kinetic energy and the turbulent dissipation rate with a turbulence intensity $I_{u}$ of $5 \%$ at the inlet. The drag law chosen is the Simmer-like model with inclusion diameter $d_{i}$ of $10^{-3} \mathrm{~m}$ for bubbles and drops.

a. Analysis of Mass Flow Rate and Mass of Water in the Dome.-The inlet and the outlet mass flow rates and the mass of water in the dome are represented in Fig. 7. Until $t=0.823 \mathrm{~s}$, the outlet mass flow rate of water is lower than the inlet one: the mass of water increases in the dome and occupies approximately $90 \%$ of the dome volume to the maximum. This is the dome filling phase. Then, from $t=0.823$ to $1 \mathrm{~s}$, the outlet mass flow rate is equal to the inlet one, and so the mass of water in the dome is constant. Finally, from $t=1 \mathrm{~s}$, the outlet mass flow rate becomes higher than the inlet one: the mass of water slowly decreases in the dome. This is the dome emptying phase.

b. Analysis of the Dome Pressure.-The experimental and the numerical dome pressures are shown by Fig. 8. First, it can be observed that the temporal evolutions of the measured and the simulated dome pressures are in good qualitative agreement. Nonetheless, the maximum is different: the numerical pressure shows more intense fluctuations and is larger. The difference in pressure between the experimental and the numerical results is estimated to be

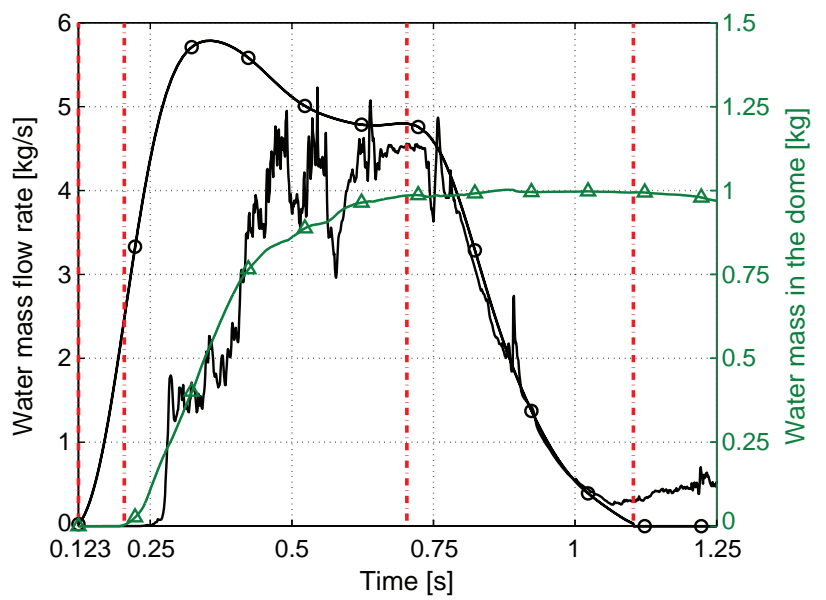

Fig. 7 Temporal evolution of the water mass flow rates (on the left vertical axis) and the water mass in the dome (on the right vertical axis). ——, inlet water mass flow rate; — $\_$, outlet water mass flow rate; $\triangle$, water mass in the dome. 


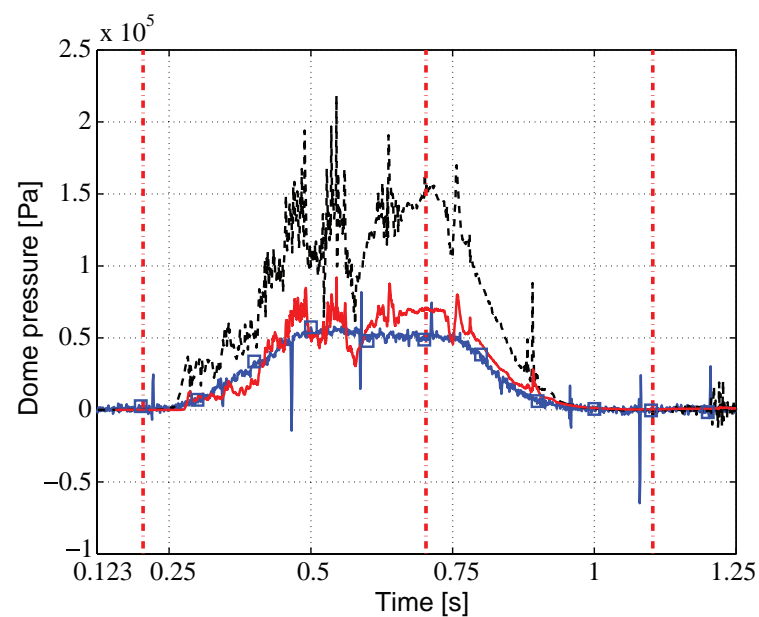

Fig. 8 Temporal evolution of the dome pressure. $\square$, experimental pressure; ---- , predicted pressure of the complete calculation; - , 1-D pressure drop model prediction from the outlet mass flow rate of the complete calculation.

$0.6 \times 10^{5} \mathrm{~Pa}$ on average at the plateau; that is to say, the numerical pressure is twice as high as the experimental pressure.

To understand the pressure overevaluation, a test has been carried out with a compressible gas simulation: it does not decrease the difference in pressure between the experimental and the numerical results. However, an analysis of grid independence on an isolated injector enables us to give more explanations about the difference in pressure.

The computational test case domain, shown by Fig. 9a, is composed of a dome upstream of an isolated injector. The test case injector is identical to the complete geometry injector. Concerning the test case dome, its inlet surface area equals $1 / N$ of the complete dome one, and its height is half of the complete dome one. Water is injected at the top of the dome with the mass flow rate $Q_{\mathrm{Ref}}^{*}=Q_{\mathrm{Ref}} / N=0.046 \mathrm{~kg} / \mathrm{s}$, in a domain initially filled with water. For this study, incompressible one-phase flow (with water) is considered, without heat and mass transfer. The $k-\varepsilon$ turbulence model is activated.

Table 1 shows the different mesh refinement cases considered. The term "reference" in case 1 corresponds to the level of mesh refinement in the complete geometry. This mesh is chosen as the reference, and the meshes of all other cases are described compared with this reference mesh. The designation "converged injector" refers to a preliminary analysis of grid independence conducted on an isolated injector (without the dome upstream). The injector mesh of the complete geometry (composed of 348 hexahedra) has been refined successively in all the directions. The results (not presented here) reveal that mesh convergence is achieved for an injector of $1.425 \times 10^{6}$ hexahedra, and so for the analysis of grid independence the reference injector mesh and the "converged" injector mesh are tested with a dome mesh more and more refined. It has to be mentioned that case 5 is an optimized mesh, where only the interest zones are refined.

Figure $9 \mathrm{~b}$ shows the relative pressure along the injector central axis for the cases listed in Table 1. First of all, the more the mesh is refined, the smoother the relative pressure is. The mesh convergence is achieved for the three last cases, the curves of which are mixed up. Additionally, the pressure drop with a mesh refined enough is reduced by $45 \%$, which explains the main part of the difference in pressure between the experimental and the numerical results. Moreover, Fig. 8 shows that dome pressure prediction using the onedimensional (1-D) pressure drop model (based on correlations like Darcy-Weisbach, Blasius, and Borda-Carnot) from the outlet mass flow rate of water given by the complete calculation is well estimated.

The study on an isolated injector enables us to clearly highlight that the pressure drop is very sensitive to the resolution of the flowfield in the sudden contraction region upstream of the injector and not to the prediction of the flow in the injector. Thus, this study shows that the mesh refinement in the dome has a crucial influence on the pressure and, more particularly, that the zone of the sudden contraction region upstream of the injectors has to be meshed very carefully.

The influence of mesh refinement is large on the pressure. If the necessary level of mesh refinement of case 5 was applied to the complete geometry, a minimum of $300 \times 10^{6}$ hexahedra would be required to mesh the whole domain. Given the current limits of the computing resources, this is difficult to carry out. Indeed, for $300 \times$ $10^{6}$ hexahedra, the local CPU time of the calculation would be three months on 8000 cores, to reach the physical time of $1.15 \mathrm{~s}$. However, during this study, it was not possible to have access to more than 512 cores, regardless of the high-performance computing resources chosen. Moreover, the present version of NEPTUNE CFD used for this study cannot take into account more than $4 \times 10^{6}$ hexahedra.

c. Analysis of Wet Injectors.-After having studied globally the flow, it is interesting to locally focus on the evolution of wet injectors to compare the numerical thresholds with the theoretical wet law. Figure 10 shows the number fraction of wet injectors $\chi$ for different levels of the mass flow rate of water (from 0.0001 to $100 \%$ ) and the

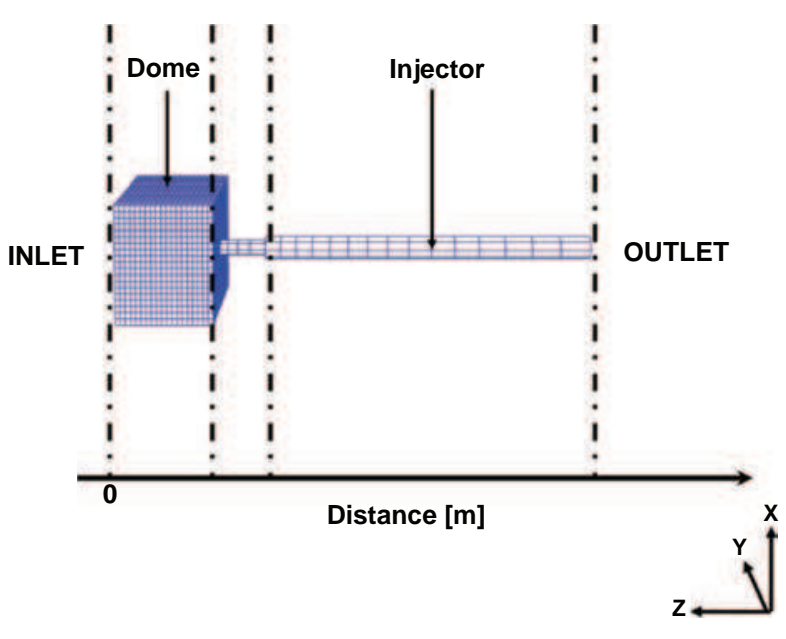

a) Test case domain with the different zones

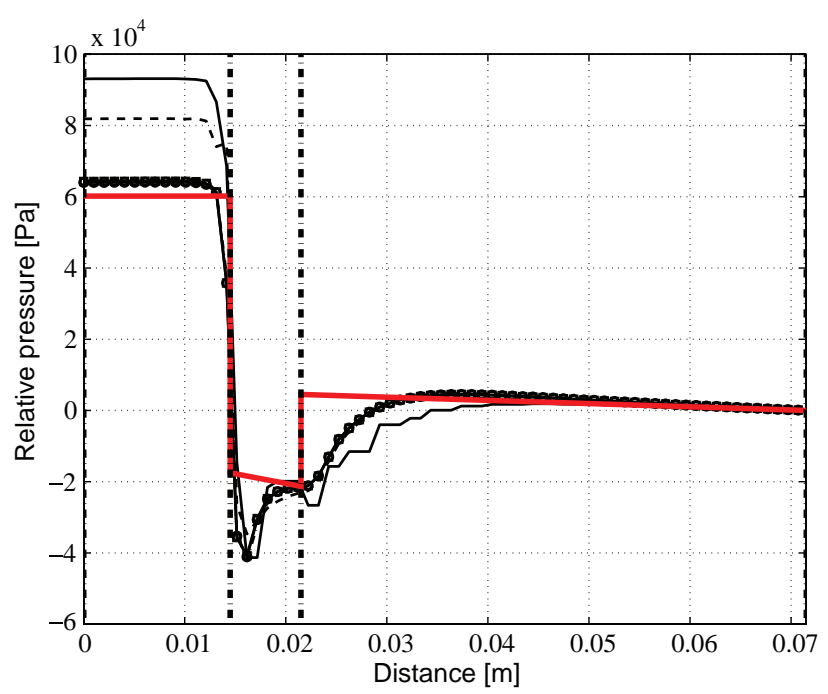

b) Relative pressure along the injector central axis

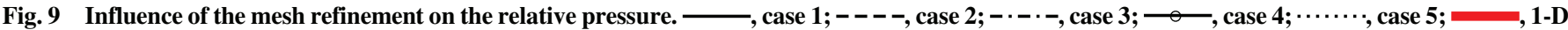
pressure drop model prediction. 
Table 1 Presentation of mesh refinement cases

\begin{tabular}{ccc}
\hline \hline Case & Mesh refinement & Number of hexahedra \\
\hline 1 & Reference injector mesh with reference dome mesh (constant mesh refinement) & $7207(\approx 348+6859)$ \\
2 & Converged injector mesh with slightly finer dome mesh (constant mesh refinement) & $1.543987 \times 10^{6}\left(\approx 1,425 \times 10^{6}+118,000\right)$ \\
3 & Converged injector mesh with finer dome mesh (constant mesh refinement) & $2.296158 \times 10^{6}\left(\approx 1,425 \times 10^{6}+871,000\right)$ \\
4 & Converged injector mesh with very fine dome mesh (constant mesh refinement) & $2.674833 \times 10^{6}\left(\approx 1,425 \times 10^{6}+1,249 \times 10^{6}\right)$ \\
5 & Converged injector mesh conformly connected with very fine dome mesh & $1.765009 \times 10^{6}\left(\approx 1.425 \times 10^{6}+339,000\right)$ \\
& (optimized mesh refinement) & \\
\hline \hline
\end{tabular}

theoretical experimental wet law. There is a satisfactory agreement between the experimental wet law and the numerical threshold chosen, except for the threshold of $100 \%$. Additionally, the visualization of all thresholds shows that some injectors have a very large mass flow rate of water: for example, at $t=0.475 \mathrm{~s}, 20 \%$ of injectors have a mass flow rate of water higher than $100 \% Q_{\mathrm{Ref}}^{*}$, whereas $80 \%$ of the rest have a value of $10 \% Q_{\mathrm{Ref}}^{*}$ or more. There is also an imbalance of the mass flow rate of water at the injectors outlet, confirmed by the statistical analysis.

For more information on the wet injectors, refer to Table 2, which lists the experimental and the numerical values for criteria $b$ and $c$ according to the threshold chosen. Except the threshold of $1 \%$, the numerical results are in very good agreement for criterion $b$, which represents the slope beginning at the first order. Nonetheless, the relative deviation for criteria $c$, which represents the injection slope, is very great. It has to be mentioned that the experimental law is a firstorder model and that the numerical slope remains subjective. Criterion $c$ is really sensitive to the way in which the slope is calculated. It is more interesting to base on the shape of the curves to have a more qualitative appreciation.

d. Statistical Characterization at Injectors Outlet.-A statistical study has been carried out in order to better characterize the flow at the injectors outlet. Figure 11 shows the distribution functions of $Q_{1}^{(n)}$, the outlet mass flow rate of water for injector $n$, normalized by $Q_{\mathrm{Ref}}^{*}$. For example, at $t=0.5 \mathrm{~s}, 95 \%$ of injectors have an outlet mass flow rate lower than $Q_{\mathrm{Ref}}^{*}$. For $0.3<t<0.9 \mathrm{~s}$, the distribution is spread, which translates to a heterogeneous distribution of mass flow rates of water. Apart from this time interval, the distribution is narrow, which translates to a more homogeneous distribution of mass flow rates of water.

Figure 12 shows the correlation distribution between the outlet mass flow rate $Q_{1}^{(n)}$ and the outlet velocity $V_{1}^{(n)}$ for water at $t=0.5 \mathrm{~s}$. This figure clearly shows that the flow at the outlet is a two-phase flow, with a nonhomogeneous distribution in mass flow rate (which can vary between 0 and $0.1 \mathrm{~kg} / \mathrm{s}$ ) and in the volume fraction for water.

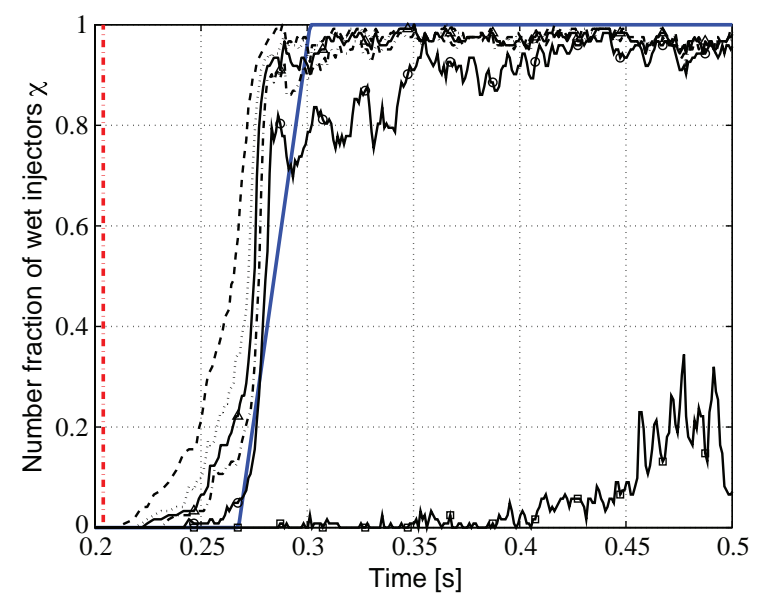

Fig. 10 Influence of the threshold on the temporal evolution of the number fraction of wet injectors $\chi$. - experimental wet law; - - - threshold $0.0001 \% ; \cdots \ldots .$. , threshold $0.01 \% ; \triangle \_$, threshold $0.1 \%$; $-\cdot-\cdot$, threshold $1 \%$; $\longrightarrow$, threshold $10 \% ; \square$, threshold $100 \%$.
Table 2 Influence of the threshold chosen on the criteria $b$ and $c$

\begin{tabular}{lcccc}
\hline \hline Threshold & Criteria & $\begin{array}{c}\text { Numerical } \\
\text { results }\end{array}$ & $\begin{array}{c}\text { Experimental } \\
\text { data }\end{array}$ & $\begin{array}{c}\text { Relative } \\
\text { deviation, \% }\end{array}$ \\
\hline $0.0001 \%$ & $b(\mathrm{~s})$ & 0.253 & 0.267 & 5.2 \\
& $c(\chi / \mathrm{s})$ & 42.7 & 29.7 & -43.8 \\
$0.01 \%$ & $b(\mathrm{~s})$ & 0.266 & 0.267 & 0.4 \\
& $c(\chi / \mathrm{s})$ & 86.9 & 29.7 & -192.6 \\
$0.1 \%$ & $b(\mathrm{~s})$ & 0.270 & 0.267 & -1.1 \\
& $c(\chi / \mathrm{s})$ & 112.9 & 29.7 & -280.1 \\
$1 \%$ & $b(\mathrm{~s})$ & 0.150 & 0.267 & 43.8 \\
& $c(\chi / \mathrm{s})$ & 123.9 & 29.7 & -317.2 \\
$10 \%$ & $b(\mathrm{~s})$ & 0.274 & 0.267 & -2.6 \\
& $c(\chi / \mathrm{s})$ & 74.9 & 29.7 & -152.2 \\
\hline \hline
\end{tabular}

For the reference case, the temporal evolutions of the mass flow rate, the mass, the pressure, and the number fraction of wet injector numbers $\chi$ have been explained in detail. In the following results, only the more pertinent figures are presented.

\section{B. Influence of the Turbulence Modeling}

The Reynolds number at injection (when the valve is fully open) is about $3 \times 10^{5}$, and so the flow studied should be fully turbulent. A step of this work focuses on the influence of the turbulence modeling. More precisely, the impact of the $k-\varepsilon$ turbulence model is globally and locally analyzed, through three cases: 1) a case without turbulence modeling, 2) another case with the $k-\varepsilon$ turbulence model with a turbulence intensity $I_{u}$ of $5 \%$ at the inlet, and 3 ) a last case with the $k-\varepsilon$ turbulence model with a larger turbulence intensity $I_{u}=10 \%$ at the inlet.

The case presented here is performed for a Weber number $W e_{\text {Ref }}=4.72 \times 10^{4} \mathrm{~m} / \mathrm{s}$, that is to say, $V_{\operatorname{Ref}}=11.5 \mathrm{~m} / \mathrm{s}$ and $Q_{\mathrm{Ref}}=5.65 \mathrm{~kg} / \mathrm{s}$. The drag law chosen is the Simmer-like model with inclusion diameter $d_{i}=10^{-3} \mathrm{~m}$.

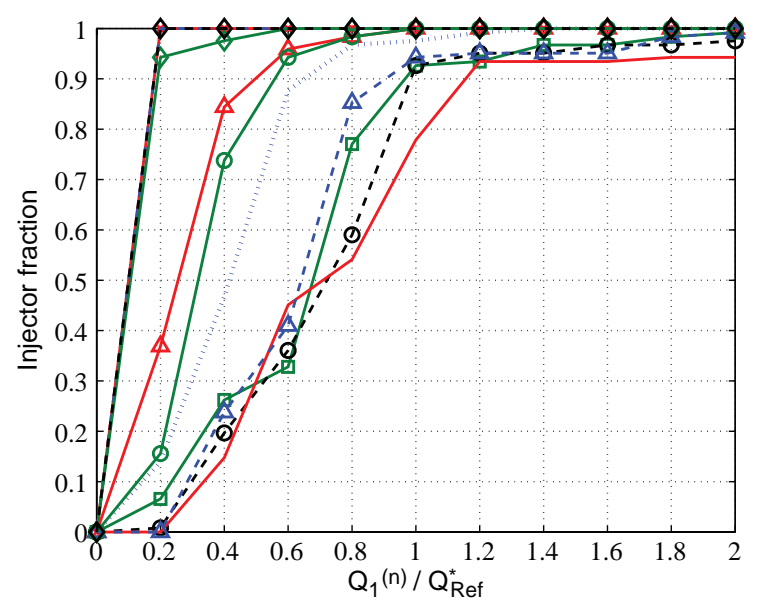

Fig. 11 Distribution functions of the outlet water mass flow rate for an injector $Q_{1}^{(n)}$ normalized by $Q_{\mathrm{Ref}}^{*}{ }^{-} \leftarrow, t=0.2 \mathrm{~s} ;-\cdot-\cdot-$, $t=0.25 \mathrm{~s} ; \quad \smile, \quad t=0.275 \mathrm{~s} ; \quad----, \quad t=0.28 \mathrm{~s} ; \quad \triangle$, $t=0.3 \mathrm{~s} ; \cdots \cdots \cdots, t=0.4 \mathrm{~s} ; \square, t=0.5 \mathrm{~s} ;--{ }^{-},-, t=0.6 \mathrm{~s} ; \square$, $t=0.7 \mathrm{~s} ;--\triangle-, t=0.8 \mathrm{~s} ; \multimap, t=0.9 \mathrm{~s} ;-\backsim-, t=1 \mathrm{~s}$. 


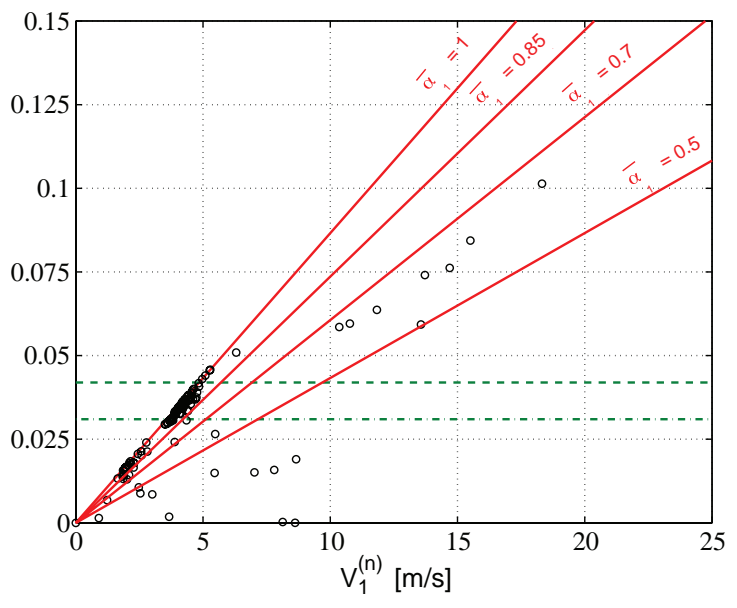

Fig. 12 Correlation distribution between the outlet water mass flow rate $Q_{1}^{(n)}$ and the outlet water velocity $V_{1}^{(n)}$ at $t=0.5 \mathrm{~s}$. $\bigcirc$, complete calculation; -, $\bar{\alpha}_{1} \rho_{1} S^{(n)} V_{1}^{(n)} ;----$, inlet mass flow rate of water divided by $N ; \cdot \cdot-\cdot-$, outlet mass flow rate of water divided by $N$.

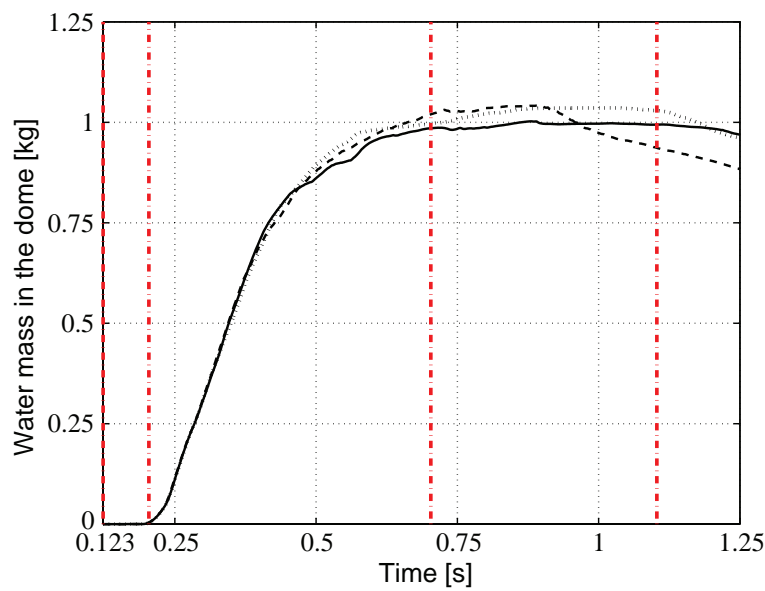

Fig. 13 Influence of the turbulence modeling on the temporal evolution of the water mass in the dome. -- --, no turbulence modeling; $k-\varepsilon$ turbulence model with $I_{u}=5 \% ; \cdots \cdots, k-\varepsilon$ turbulence model with $I_{u}=10 \%$.

The turbulence modeling and the inlet turbulence intensity have no decisive impact globally on the temporal evolution of the outlet mass flow rate of water. Nonetheless, observing more precisely the mass of water in the dome (presented in Fig. 13) shows a difference of behavior when the valve begins to close. Emptying the dome is a little faster without turbulence modeling. Additionally, the turbulence modeling and the inlet turbulence intensity have little influence on the dome pressure and on the wet injector numbers $\chi$, as confirmed by criteria $b$ and $c$ listed in Table 3 .

In conclusion, activating the turbulence modeling or modifying the inlet turbulence intensity has no macroscopic or local effect.

\section{Influence of the Interfacial Momentum Transfer Modeling}

In this section, the influence of the interfacial momentum transfer modeling is studied. First, two models are tested: the Simmer-like law and the LIM. Then the influence of inclusion diameter $d_{i}$, parameter of the Simmer-like law, is more precisely studied.

The case presented here is performed for a reference Weber number $W e_{\text {Ref }}=4.72 \times 10^{4} \mathrm{~m} / \mathrm{s}$, that is to say, $V_{\text {Ref }}=11.5 \mathrm{~m} / \mathrm{s}$ and $Q_{\operatorname{Ref}}=5.65 \mathrm{~kg} / \mathrm{s}$. The $k-\varepsilon$ turbulence model is activated with a turbulence intensity $I_{u}$ of $5 \%$ at the inlet.

\section{Influence of the Drag Law}

In this section, the influence of two drag laws is studied: the Simmer-like law (with inclusion diameter $d_{i}=10^{-3} \mathrm{~m}$ ) and the LIM.

The temporal evolutions of the outlet mass flow rate of water and the mass of water in the dome (Fig. 14) have the same behavior until $t=0.784 \mathrm{~s}$. Then their evolutions differ: the outlet mass flow rate of water shows more frequent and intense fluctuations with LIM, which is why the mass of water in the dome is smaller with LIM. Until $t=0.784 \mathrm{~s}$, the dome is filling before reaching a maximum filling to $90 \%$. After $t=0.784 \mathrm{~s}$, the difference of behavior is increased between the two drag models: the dome drains off water much faster with LIM. This different behavior can be explained by a mechanical friction between liquid and gas phases, which is higher with the Simmer-like law, a separate phases model. That is why the air entrainment by water is higher. Thus, the outlet volume flow rate of air is higher. As the total outlet volume flow rate is constant, due to the hypothesis of incompressible flow, the outlet volume flow rate of water is lower with the Simmer-like model.

A similar assessment can be made for the dome pressure. After a similar phase, the two pressures differ: on the one hand, the dome pressure with LIM is higher, and on the other hand the pressure with LIM shows more frequent and intense fluctuations, with a relative deviation from pressure with the Simmer-like model reaching $270 \%$ at worst.

The global effects highlighted before are also manifested locally on the evolution of the number fraction of wet injectors $\chi$. Even if the values of criterion $b$, which represents the date of the beginning of the slope, are rather close, the values of criterion $c$, the injection slope, are always lower with LIM, as it is confirmed in Table 4. Moreover, all the injectors are not wet at the same time with LIM, contrary to the Simmer-like model, as shown, for instance, by Fig. 15 for the threshold of $0.01 \%$.

To conclude, notable differences of behavior between the two drag models are noticed globally and locally. Thus, the drag law model has a major impact on the results. Even if the Simmer-like model seems to be less physical than LIM, it is preferred. Indeed, LIM, based on a free surface detection, is in the course of validation at EDF Research and Development: for the moment, LIM is more adapted to stationary flows with structured mesh, contrary to our cases whose water-air interface moves fast in an unstructured mesh. Additionally, it should be noted that the coarse mesh used in the present study might also be responsible for numerical errors that might be compensated for by modeling errors due to the inadequate Simmer-like drag model.

Table 3 Influence of the turbulence modeling on the criteria $b$ and $c$, according to the threshold chosen

\begin{tabular}{|c|c|c|c|c|c|}
\hline Threshold & Criteria & No turbulence modeling & $k-\varepsilon$ turbulence model with $I_{u}=5 \%$ & $k-\varepsilon$ turbulence model with $I_{u}=10 \%$ & Experimental data \\
\hline \multirow[t]{2}{*}{$0.0001 \%$} & $b(\mathrm{~s})$ & 0.252 & 0.253 & 0.255 & 0.267 \\
\hline & $c(\chi / s)$ & 39.8 & 42.7 & 44.0 & 29.7 \\
\hline \multirow[t]{2}{*}{$0.01 \%$} & $b(\mathrm{~s})$ & 0.261 & 0.266 & 0.266 & 0.267 \\
\hline & $c(\chi / \mathrm{s})$ & 57.4 & 86.9 & 74.4 & 29.7 \\
\hline \multirow[t]{2}{*}{$0.1 \%$} & $b(\mathrm{~s})$ & 0.266 & 0.270 & 0.270 & 0.267 \\
\hline & $c(\chi / s)$ & 71.4 & 112.9 & 97.4 & 29.7 \\
\hline \multirow[t]{2}{*}{$1 \%$} & $b(\mathrm{~s})$ & 0.148 & 0.150 & 0.150 & 0.267 \\
\hline & $c(\chi / \mathrm{s})$ & 101.3 & 123.9 & 100.8 & 29.7 \\
\hline \multirow[t]{2}{*}{$10 \%$} & $b(\mathrm{~s})$ & 0.273 & 0.274 & 0.275 & 0.267 \\
\hline & $c(\chi / s)$ & 93.8 & 74.9 & 99.3 & 29.7 \\
\hline
\end{tabular}




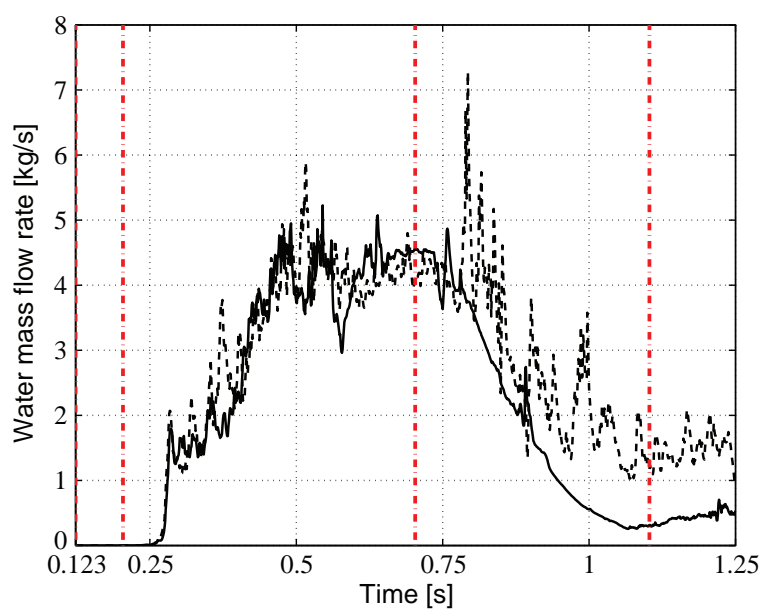

a) Outlet water mass flow rate

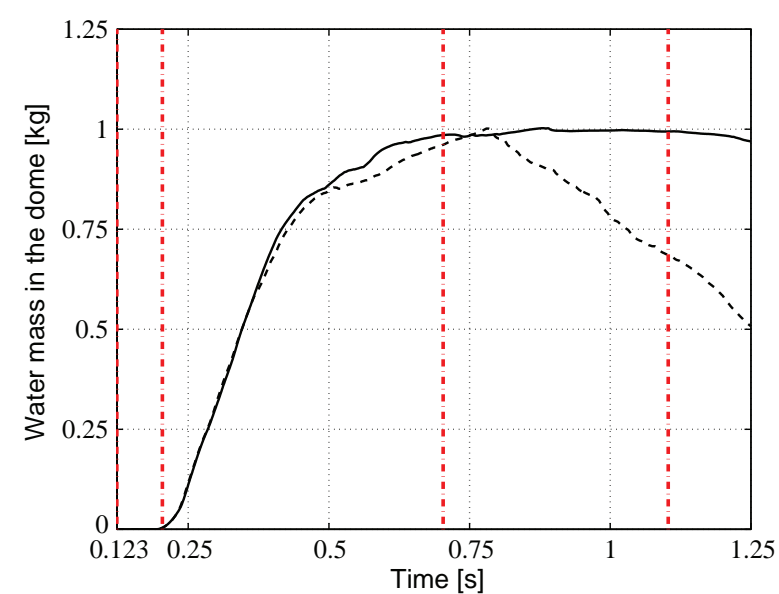

b) Water mass in the dome

Fig. 14 Influence of the drag law on the temporal evolution of the outlet water mass flow rate and the water mass in the dome. $\left(d_{i}=10^{-3} \mathrm{~m}\right) ;----$, LIM.

Table 4 Influence of the drag law on the criteria $b$ and $c$, according to the threshold chosen

\begin{tabular}{ccccc}
\hline \hline Threshold & Criteria & Simmer-like law & LIM & Experimental data \\
\hline $0.0001 \%$ & $b(\mathrm{~s})$ & 0.253 & 0.240 & 0.267 \\
& $c(\chi / \mathrm{s})$ & 42.7 & 25.2 & 29.7 \\
$0.01 \%$ & $b(\mathrm{~s})$ & 0.266 & 0.258 & 0.267 \\
& $c(\chi / \mathrm{s})$ & 86.9 & 47.5 & 29.7 \\
$0.1 \%$ & $b(\mathrm{~s})$ & 0.270 & 0.262 & 0.267 \\
& $c(\chi / \mathrm{s})$ & 112.9 & 51.2 & 29.7 \\
$1 \%$ & $b(\mathrm{~s})$ & 0.150 & 0.145 & 0.267 \\
\multirow{2}{*}{$10 \%$} & $c(\chi / \mathrm{s})$ & 123.9 & 68.1 & 29.7 \\
& $b(\mathrm{~s})$ & 0.274 & 0.270 & 0.267 \\
& $c(\chi / \mathrm{s})$ & 74.9 & 56.4 & 29.7 \\
\hline \hline
\end{tabular}

\section{Influence of the Inclusion Diameter in the Simmer-Like Law}

After having tested the two drag models (the Simmer-like law and the LIM), the influence of inclusion diameter $d_{i}$, which is a parameter of the Simmer-like law, is studied in this section. Three diameters are tested: $10^{-5}, 10^{-4}$, and $10^{-3} \mathrm{~m}$. It has to be noted that reducing the inclusion diameter amounts to increasing the drag force [as shown by Eqs. (4-6)].

A preliminary analysis (not presented here) shows that the mean outlet mass flow rate of water is almost the same for the three cases, let the value of the inclusion diameter. However, the behavior differs as regards the mass of water in the dome (Fig. 16). Unlike the numerical

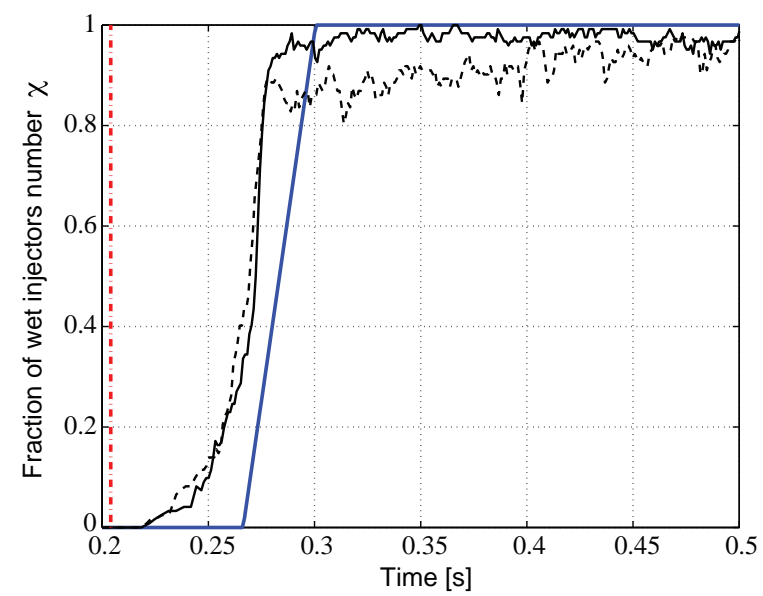

Fig. 15 Influence of the drag law on the temporal evolution of the number fraction of wet injectors $\chi$, for the threshold of $0.01 \%$. $\longrightarrow$, experimental wet law; $\longrightarrow$, Simmer-like model $\left(d_{i}=10^{-3} \mathrm{~m}\right) ;----$, LIM. results with $d_{i}=10^{-3}$ and $10^{-5} \mathrm{~m}$, where the mass of water in the dome continues to increase until $1 \mathrm{~s}$, a decrease in the mass of water in the dome is observed with $d_{i}=10^{-4} \mathrm{~m}$ from $0.45 \mathrm{~s}$. Additionally, it can be noticed that the temporal evolution of the mass of water is smoother with the lower inclusion diameter $d_{i}=10^{-5} \mathrm{~m}$, because

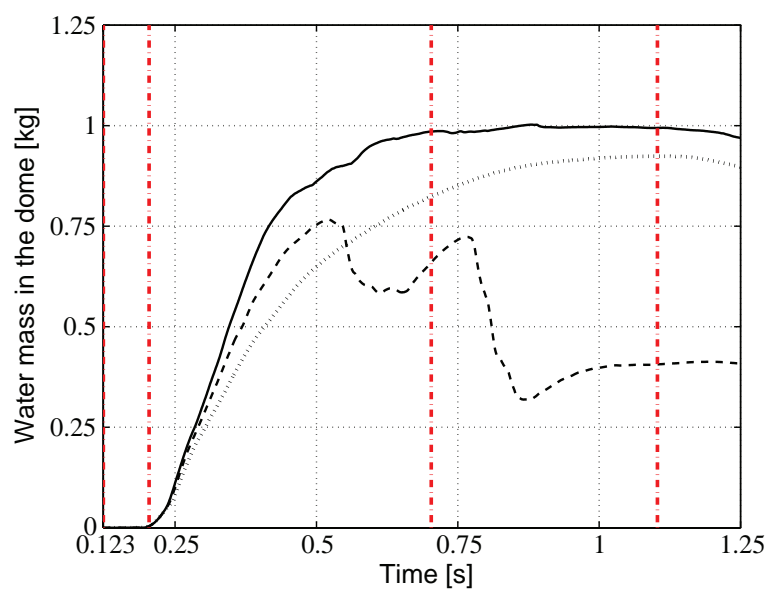

Fig. 16 Influence of the inclusion diameter in the Simmer-like law on the temporal evolution of the water mass in the dome. experimental wet law; $\cdots \cdots, d_{i}=10^{-5} \mathrm{~m} ;----, d_{i}=10^{-4} \mathrm{~m}$; $\underline{-}, d_{i}=10^{-3} \mathrm{~m}$.

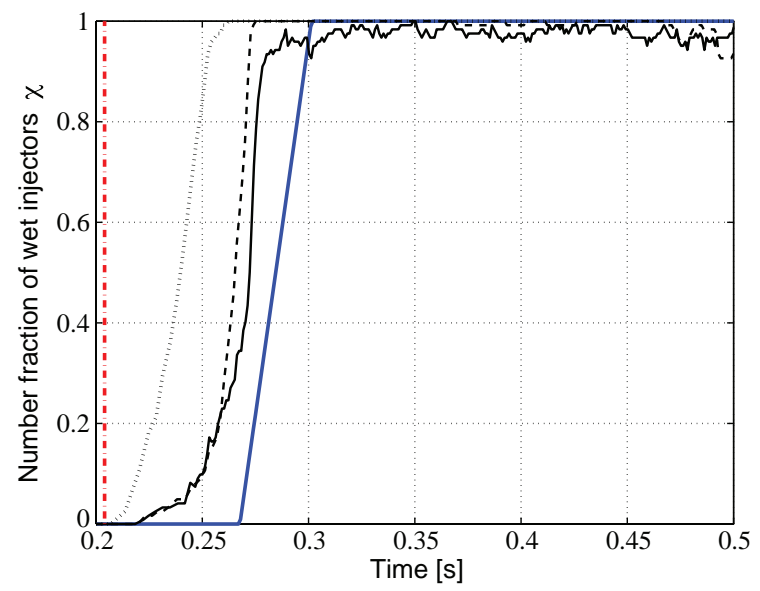

Fig. 17 Influence of the inclusion diameter in the Simmer-like law on the temporal evolution of the number fraction of wet injectors $\chi$, for the threshold of $0.01 \%$. -,$d_{i}=10^{-3} \mathrm{~m} ;----$, $d_{i}=10^{-4} \mathrm{~m} ; \cdots \cdots \cdots, d_{i}=10^{-5} \mathrm{~m}$. 
Table 5 Influence of the inclusion diameter in the Simmer-like law on the criteria $b$ and $c$, according to the threshold chosen

\begin{tabular}{cccccc}
\hline \hline Threshold & Criteria & $d_{i}=10^{-5} \mathrm{~m}$ & $d_{i}=10^{-4} \mathrm{~m}$ & $d_{i}=10^{-3} \mathrm{~m}$ & Experimental data \\
\hline $0.0001 \%$ & $b(\mathrm{~s})$ & 0.216 & 0.247 & 0.253 & 0.267 \\
& $c(\chi / \mathrm{s})$ & 27.0 & 42.1 & 42.7 & 29.7 \\
$0.01 \%$ & $b(\mathrm{~s})$ & 0.222 & 0.254 & 0.266 & 0.267 \\
& $c(\chi / \mathrm{s})$ & 29.9 & 46.3 & 86.9 & 29.7 \\
$0.1 \%$ & $b(\mathrm{~s})$ & 0.236 & 0.259 & 0.270 & 0.267 \\
& $c(\chi / \mathrm{s})$ & 50.1 & 59.5 & 112.9 & 29.7 \\
$1 \%$ & $b(\mathrm{~s})$ & 0.124 & 0.140 & 0.150 & 0.267 \\
\multirow{2}{*}{$10 \%$} & $c(\chi / \mathrm{s})$ & 59.5 & 60.4 & 123.9 & 29.7 \\
& $b(\mathrm{~s})$ & 0.260 & 0.270 & 0.274 & 0.267 \\
\hline \hline
\end{tabular}

the mechanical friction is larger. The same effects can be observed on the temporal evolution of the dome pressure.

As an example, the temporal evolution of the number fraction of wet injectors $\chi$ is shown by Fig. 17 for the threshold of $0.01 \%$. The lower the diameter is, the smoother the evolution of $\chi$ is and the earlier the maximum of $\chi$ is reached. There are few differences between $d_{i}=10^{-3}$ and $10^{-4} \mathrm{~m}$, except for the maximal number fraction of wet injectors. The result for $d_{i}=10^{-5} \mathrm{~m}$ is very different from the experimental law. Criterion $b$ listed in Table 5 shows a weak trend of the injectors wetting to arrive earlier, whereas criterion $c$ shows that water comes out of injectors faster, when the inclusion diameter decreases.

Reducing $d_{i}$ homogenizes the water-air mixture. Indeed, the inclusions are smaller, and so the exchange surface area and the friction are higher. That is why it is well mixed and water comes out of injectors faster. To conclude, the inclusion diameter of $10^{-3} \mathrm{~m}$ seems to be the optimal choice regarding the experimental data in our case.

\section{Conclusions}

The feeding of the LOX dome of a cryogenic rocket engine is a decisive stage of the engine reignition. However, the required flight conditions to study this problem are difficult to reproduce by experimental ground tests. To better understand and to correctly predict the feeding process, experiments are conducted with substitution fluids (air and water), without heat and mass transfer. The study presented demonstrates the feasibility of a 3-D unsteady twophase flow calculation with the code NEPTUNE_CFD to simulate the filling of the experimental LOX dome mockup, taking into account the industrial geometry and the preponderant physical phenomena.

All the necessary mathematical modelings have been performed, in order to obtain the proper inlet conditions at the feeding pipe inlet for the numerical simulations in coherence with the experiments. The simulations have then been conducted in order to compare the numerical results with the experimental data. The numerical results are in global agreement with the experimental results, except the pressure inside the dome, due to the coarse meshing of the geometry. The fine mesh, on the other hand, is too costly to be performed in the complete geometry.

This work also focuses on the influence of the drag models (the Simmer-like law and the LIM) and the turbulence modeling on the flow dynamics. The turbulence modeling or the inlet turbulence intensity have been shown to have no macroscopic or local effect on the mass flow rate of water, the mass of water in the dome, and the dome pressure. The drag model has a major impact on the results as much globally as locally, unlike the turbulence modeling. The Simmer-like model is preferred in comparison to the LIM model, due to a better agreement with the experimental data. Moreover, it has to be highlighted that the Simmer-like model is very sensitive to its parameter $d_{i}$, the inclusion diameter. In our case, the inclusion diameter of $10^{-3} \mathrm{~m}$ seems to be in good agreement with the experimental data.

Additionally, the study conducted on an isolated injector clearly highlights that the pressure drop is very sensitive to the resolution of the flowfield in the sudden contraction region upstream of the injector and not to the prediction of the flow in the injector. Thus, it would be very interesting to carry out new numerical simulations, by improving the meshing in this sudden contraction region. To have quantitative information and to improve the representativeness of the flow in the mockup, the mesh should be from 100 to 200 times more refined than the coarse version of the mesh used for this study. This performance will be possible in the new version of the code.

\section{Acknowledgments}

NEPTUNE_CFD is developed in the framework of the NEPTUNE project, financially supported by the Commissariat à l'Énergie Atomique, Électricité de France (EDF), Institut de Radioprotection et de Sûreté Nucléaire, and AREVA-NP. The authors would like to acknowledge SAFRAN Snecma and the Centre National d'Études Spatiales (CNES) for funding this study through a Ph.D. CNES program and the scientific support of P. Boivin (Snecma), J. Laviéville, and N. Méchitoua (EDF Research and Development). This work was performed using high-performance computing resources from CAlcul en MIdi-Pyrénées (CALMIP) (Grant No. 2012-P0111).

\section{References}

[1] Alliot, P., Dalbies, E., Pacros, A., and Ruault, J.-M., "Overview of the Development Progress of the Ariane 5 Upper Stage Vinci Engine," 53rd International Astronautical Congress - The World Space Congress, International Astronautical Federation, Paris, France, 2002, p. 3, http:// anne.pacros.pagesperso-orange.fr/career/IAC-02-S-1-03.pdf [retrieved 9 Dec. 2013]

[2] Pacros, A., Follet, J., and Vieille, B., "Microgravity Activities for the Vinci Engine Re-Ignition Capability," Proceedings of the Microgravity Transport Progresses in Fluid, Thermal, Biological and Materials Sciences III, Davos, Switzerland, 2003, http://anne.pacros.pagespersoorange.fr/career/Davos-MTP-03-34.pdf [retrieved 9 Dec. 2013]

[3] Hérenger, N., "Étude Expérimentale du Transitoire de Remplissage des Cavités d'injection des Organes de Combustion du Moteur VINCI," Ph.D. Thesis, LEGI, Grenoble, France, 2012.

[4] Drew, D. A., "Mathematical Modeling of Two-Phase Flow," Annual Review of Fluid Mechanics, Vol. 15, 1983, pp. 261-291. doi:10.1146/annurev.fl.15.010183.001401

[5] Bel Fdhila, R., and Simonin, O., "Eulerian Prediction of a Turbulent Bubbly Flow in a Sudden Pipe Expansion," Proceedings of the 6th Workshop on Two-Phase Flow Predictions, Sommerfeld, M., Bilateral Seminars of the International Bureau/Forschungszentrum Jülich $\mathrm{GmbH}$, Vol. 14, 1992, pp. 264-273, http://scholar.google.com/scholar? cluster $=8517422620745892792 \&=$ en $\&=$ scholarr $\quad$ [retrieved 9 Dec. 2013].

[6] Simonin, O., "Continuum Modelling of Dispersed Two-Phase Flows," Combustion and Turbulence in Two-Phase Flows, Lecture Series 199602, von Karman Institute for Fluid Dynamics, Rhode Saint Genèse, Belgium, 1996.

[7] Méchitoua, N., Jennesson, B., Schneider, J.-P., Luck, M., and Valette, E., "Assessment of NEPTUNE_CFD Code for Some Free Surface Flows Interesting Fluvial Hydraulic," 7th International Conference on Multiphase Flow, ICMF, Tampa, 2010.

[8] Laviéville, J., and Coste, P., "Numerical Modelling of Liquid-Gas Stratified Flows Using Two-Phase Eulerian Approach," FVCA5, Aussois, France, 2008. 
[9] Coste, P., "A Large Interface Model for Two-Phase CFD," Nuclear Engineering and Design, Vol. 255, Feb. 2013, pp. 38-50. doi:10.1016/j.nucengdes.2012.10.008

[10] Fabre, J., Masbernat, L., and Suzanne, C., "Stratified Flows, Part 1: Local Structure," Multiphase Science and Technology, Vol. 3, Nos. 1-4, 1987, pp. 285-301.

[11] Neau, H., Laviéville, J., and Simonin, O., "NEPTUNE_CFD High Parallel Computing Performances for Particle-Laden Reactive Flows," 7th International Conference on Multiphase Flow, ICMF, ICMF, Tampa, 2010, pp. 1-15.

[12] Neau, H., Fede, P., Laviéville, J., and Simonin, O., "High Performance Computing (HPC) for the Fluidization of Particule-Laden Reactive Flows," 14th International Conference on Fluidization - From Fundamentals to Products, Eds, ECI Symposium Series, The
Netherlands, 2013, http://dc.engconfintl.org/fluidization_xiv/63 [retrieved 9 Dec. 2013].

[13] Méchitoua, N., Boucker, M., Mimouni, S., Pigny, S., and Serre, G., "Numerical Simulation of Multiphase Flow with an Elliptic Oriented Fractional Step Method," Third International Symposium on Finite Volumes for Complex Applications, Porquerolles, France, 2002.

[14] Méchitoua, N., Boucker, M., Laviéville, J., Hérard, J.-M., Pigny, S., and Serre, G., "An Unstructured Finite Volume Solver for Two-Phase Water/ Vapour Flows Modeling Based on Ellipstic Oriented Fractional Step Method," 10th International Topical Meeting on Nuclear Reactor Thermal Hydraulics (NURETH-10), Seoul, South Korea, 2003.

J. Oefelein Associate Editor 